\title{
Plano Estadual de Educação de Mato Grosso do Sul: entre a gestão gerencial e a gestão democrática
}

\author{
Mato Grosso do Sul State Education Plan: management and \\ democratic management
}

\author{
Plan Estatal de Educación Mato Grosso do Sul: entre la \\ administración gerencial y gestión democrática
}

\author{
Regina Tereza Cestari de Oliveira* \\ ORCID: https://orcid.org/0000-0001-5500-7478
}

\begin{abstract}
Resumo: Este artigo apresenta resultados de pesquisa e analisa, a partir da aprovação do Plano Nacional de Educação (PNE) 2014-2024, o processo de materialização do Plano Estadual de Educação de Mato Grosso do Sul (PEE/MS), vigente, como política pública, de modo a apreender as condições objetivas em que esse processo se concretiza, ressaltando as concepções de gestão da educação em disputa, assim como a regulamentação da gestão democrática da educação. Fundamenta-se em autores que discutem os temas em questão, na análise de documentos como os planos de educação, os relatórios de monitoramento e avaliação do PEE/MS, entre outros, e em entrevistas com representantes da sociedade política e da sociedade civil do estado (Assembleia Legislativa, Secretaria de Estado de Educação e Fórum Estadual de Educação). Mostra que a ausência da normatização da gestão democrática da educação do sistema de ensino, e o modelo de avaliação de diretores escolares, por um lado, assim como mecanismos e dinâmicas de gestão participativa, por outro, expressa as concepções em disputa, traduzem as prioridades e os projetos antagônicos de educação e de sociedade.
\end{abstract}

Palavras-chave: Política educacional; Planejamento da educação; Gestão gerencial; Gestão Democrática.

Abstract: This paper presents research results and analyzes, from the approval of the National Education Plan (PNE) 2014-2024, the materialization process of the State Education Plan of Mato Grosso do Sul (PEE / MS), in force, as public policy, in order to apprehend the objective conditions in which this process materializes, emphasizing the concepts of education management in dispute, as well as the regulation of the democratic management of education. It is based on authors who discuss the issues, in the analysis of documents such as education plans, monitoring and evaluation reports of the PEE / MS, among others, and in interviews with representatives of political and civil society in the state (Legislative Assembly, State Education Secretariat and State Education Forum). It shows that the lack of standardization of the democratic management of education in the education system, and the evaluation model of school principals, on one hand, as well as mechanisms and dynamics of participatory management, on the other, expresses the contested concepts, translating the priorities and antagonistic education and society projects.

Keywords: Educational policy; Education planning; Management; Democratic management.

Resumen: Este artículo presenta resultados de investigación y análisis, desde la aprobación del Plan Nacional de Educación (PNE) 2014-2024, el proceso de materialización del Plan Estatal de Educación de Mato Grosso do Sul (PEE / MS), actual, como política pública, con el fin de aprehender las condiciones objetivas en las que se materializa este proceso, enfatizando los conceptos de gestión educativa en disputa, así como la regulación de la gestión democrática de la educación. Se basa en autores que discuten los temas, en el análisis de documentos como planes educativos, informes de seguimiento y evaluación del PEE / MS, entre

\footnotetext{
* Docente do Programa de Pós-Graduação em Educação - Mestrado e Doutorado da Universidade Católica Dom Bosco. Coordenadora do Grupo de pesquisa Políticas Públicas e Gestão da Educação (GEPPE) Doutora em Educação pela Unicamp. Pesquisadora produtividade CNPq. Docente (aposentada) da Universidade Federal de Mato Grosso do Sul (UFMS). E-mail: reginacestare@ucdb.br
} 
otros, y en entrevistas con representantes de la sociedad política y civil en el estado. (Asamblea Legislativa, Secretaría de Educación del Estado y Foro de Educación del Estado). Señala que la falta de estandarización de la gestión democrática de la educación en el sistema educativo, y el modelo de evaluación de los directores de escuela, por un lado, así como los mecanismos y dinámicas de gestión participativa, por otro, expresa los conceptos controvertidos, traduciendo las prioridades. y proyectos antagónicos de educación y sociedad. Palabras clave: Política educativa; Planificación de la educación; Administración gerencial; Gestión democrática.

\section{INTRODUÇÃO}

A Constituição Federal (CF), promulgada em 5 de outubro de 1988, ao fazer a escolha por um regime normativo e político, plural e descentralizado, consagrou princípios caros à democracia e à educação democrática.

Ela é tanto um modo de se opor ao que até então vigia em termos de medo e de despotismo, quanto uma maneira de se propor a gestação de uma nova maneira de se administrar a coisa pública ou seja sob a forma da virtude como amor pela coisa pública (CURY, 2002, p. 166-167, grifo do autor).

Há de se considerar a competência da União de elaborar um Plano Nacional de Educação (PNE), definida no art. 14 da CF de 1988 (BRASIL, 1988), reafirmada na Lei de Diretrizes e Bases da Educação Nacional (LDBEN), conforme o art. 9º ou seja: "A União incumbir-se-á de: I - elaborar o Plano Nacional de Educação, em colaboração com os Estados, o Distrito Federal e os Municípios" (BRASIL, 1996).

Ao consagrar a ideia de um plano nacional de educação, pressupõe-se que,

Um plano de Estado é, assim, um meio de unidade tanto social como política. Social, porque busca preencher com realizações as promessas e os valores que a educação encerra. Política, porque em países federativos há que haver um equilíbrio entre unidade nacional e diversidade regional. $E$ um plano, especialmente em nosso país, que conta com a obrigatoriedade da vinculação de recursos para a educação, se impõe como medida racional para maximizá-los em vista de sua aplicação finalística (CURY, 2013, p. 31-32).

Em decorrência das disposições legais, o PNE resultado do embate entre dois projetos, um oriundo da sociedade civil e outro apresentado pelo governo federal, portanto, uma escritura polêmica, ainda que com metas significativas (CURY, 2013), foi aprovado pela Lei 10.172, de 9 de janeiro de 2001 (BRASIL, 2001), sancionada com nove vetos pelo presidente, à época, Fernando Henrique Cardoso (1995-2002), do Partido da Social Democracia Brasileira (PSDB). Essas propostas expressavam concepções e prioridades educacionais distintas, no que se refere, principalmente, à abrangência das políticas, em seu financiamento e gestão. Sua aprovação, portanto, procedeu "da hegemonia governamental no Congresso Nacional que buscou traduzir a lógica das políticas educacionais em curso" (DOURADO, 2010, p. 684).

Nesse período, o governo, por meio do Ministério da Educação,

[...] efetivou políticas e lógicas de gestão, visando implementar amplo processo de reforma da educação nacional, cujas prioridades se constituíram, hegemonicamente, pela adoção de políticas focalizadas, com forte ênfase no ensino fundamental, e pela efetivação de vários instrumentos e dispositivos, visando à construção de um sistema de avaliação. (DOURADO, 2010, p. 683). 
Essas lógicas estão em consonância com a proposta neoliberal de Estado com base no entendimento de que ele entrou em crise porque gastou mais do que podia para se legitimar, seja porque tinha que atender às demandas da população por políticas sociais, provocando a crise fiscal, seja porque, ao regulamentar a economia restringe a iniciativa privada (PERONI; OLIVEIRA; FERNANDES, 2009).

A crise não é, portanto, como a explica a ideologia neoliberal, resultado da demasiada interferência do Estado, da garantia de ganhos de produtividade e da estabilidade dos trabalhadores e das despesas sociais. Ao contrário, a crise é um elemento constituinte, estrutural, do movimento cíclico da acumulação capitalista, assumindo formas específicas que variam de intensidade no tempo e no espaço. (FRIGOTTO, 1995, p. 62).

Há de se atentar para o fato de que os teóricos neoliberais "têm uma profunda suspeita com relação à democracia".

A governança pelo regime da maioria é considerada uma ameaça potencial aos direitos individuais e às liberdades constitucionais. A democracia é julgada um luxo que só é possível em condições de relativa afluência, associado a uma forte presença da classe média para garantir a estabilidade política. Em consequência, os neoliberais tendem a favorecer a governança por especialistas e elites. Dão forte preferência ao governo por ordem executiva e decisão judicial em lugar da tomada de decisões democráticas e parlamentar. (HARVEY, 2012, p.77).

Desse modo, o Estado teria que alterar sua dinâmica e funcionamento, como expresso no Plano Diretor da Reforma do Aparelho do Estado (PDRAE), que propõe a substituição do padrão burocrático de gestão pública pela administração pública gerencial, elaborado em 1995, no primeiro mandato do Governo Fernando Henrique Cardoso (1995-1998), pelo então Ministério da Administração e da Reforma do Estado (Mare) (BRASIL, 1995).

As reformas neoliberais, ao longo desse governo,

[...] desmontaram a face social do Estado e ampliaram a sua face que se constituía como garantia do capital. Seu fundamento é o liberalismo conservador redutor da sociedade a um conjunto de consumidores. Por isso, o indivíduo não mais está referido à sociedade, mas ao mercado. A educação não é mais direito social e subjetivo, mas um serviço mercantil (FRIGOTTO, 2011, p. 240).

Com o final do prazo legal de vigência do PNE 2001-2010, no segundo mandato do presidente Luiz Inácio Lula da Silva (2007-2010), o governo convocou uma Conferência Nacional de Educação (CONAE), intitulada "Construindo um Sistema Nacional Articulado de Educação: Plano Nacional de Educação, suas Diretrizes e Estratégias de Ação", realizada no período de 28 de março a $1^{10}$ de abril de 2010 e precedida de Conferências Municipais, Estaduais e do Distrito Federal que mobilizou cerca de 3,5 (três milhões e quinhentos mil) brasileiros (as). (BRASIL, 2010a).

A Conferência aconteceu em uma conjuntura ${ }^{1}$ em que forças sociais progressistas que conduziram o governo ao poder em janeiro de 2003, tinham, em sua origem, "a tarefa de alterar a natureza do projeto societário, com consequências para todas as áreas". (FRIGOTTO, 2011, p. 237).

Os movimentos da sociedade, ao longo do processo de abertura democrática na 
década de 1980, em oposição à ditadura civil-militar (1964-1985), foram se intensificando a partir da institucionalização de canais de participação dialógica, sendo que as conferências são retomadas como espaços de discussão no processo de elaboração das políticas públicas (SCAFF; OLIVEIRA, 2019) e promoveram ampla participação dos sujeitos e das organizações sociais indicando a força de uma ação coletiva no âmbito do Estado, entendido em uma concepção ampla, que abrange a sociedade política (aparelho governamental) e os organismos representativos da sociedade civil (GRAMSCI, 1984). Nesse processo, a gestão democrática da educação ganhou espaço no âmbito do movimento dos educadores e do debate acadêmico.

É importante destacar que o Documento Final da CONAE 2010 estabeleceu a criação do Fórum Nacional de Educação (FNE), bem como de Fóruns Estaduais e Municipais, entendidos como "espaços articulados de decisão e deliberação coletivas para a educação nacional” (BRASIL, 2010a), uma reivindicação histórica dos educadores, que esteve presente no debate do processo de elaboração da LDBEN, porém, sendo excluída da versão final da lei. (OLIVEIRA, 1998). Assim, em 14 de dezembro de 2010 a Portaria Ministerial no 1.407 instituiu o Fórum Nacional de Educação $(\mathrm{FNE})^{2}$, de caráter permanente, composto de 34 (tinta e quatro) representações, com a finalidade de coordenar as conferências nacionais de educação, acompanhar e avaliar a implementação de suas deliberações e promover as articulações necessárias entre os correspondentes fóruns de educação dos Estados do Distrito Fede- ral e dos municípios (BRASIL, 2010b). O FNE debateu e divulgou "mais de 40 (quarenta) notas, sobre temas e pautas educacionais fundamentais, tendo como eixo a defesa da educação pública, gratuita, laica, democrática, inclusiva e de qualidade social" (DOURADO; ARAÚJO, 2018, p. 214).

O governo encaminhou a proposta de um plano ao Congresso Nacional, sendo o Projeto de Lei identificado com o oㅜ 8.035/2010, e após amplo processo de debate, confronto de ideias, que compreendeu, em conjunto, a participação da sociedade política e da sociedade civil, o Plano Nacional de Educação foi aprovado pela Lei n 13.005, de 25 de junho de 2014, sancionada, sem vetos, pela presidente Dilma Vana Rousseff (2011-2014) (BRASIL, 2014).

Nesse governo, ocorreu a segunda edição da CONAE "O PNE na Articulação do Sistema Nacional de Educação: Participação Popular, Cooperação Federativa e Regime de Colaboração", de 19 a 23 de novembro de 2014, organizada pelo Fórum Nacional de Educação, com atividades em sete eixos, registrada a participação de 3.958 (três mil e novecentos e cinquenta e oito) pessoas (CONAE, 2014).

O processo de elaboração do PNE demonstra ser a primeira grande experiência de participação popular no planejamento educacional nacional em processo conduzido pelo Estado brasileiro que resultou em um plano aprovado por lei federal, como afirma Souza (2016). O PNE expressa os consensos, as contradições do processo, a disputa de concepções na conjuntura em que foi construído.

1 O que define uma conjuntura não é o tempo cronológico, "mas a natureza dos acontecimentos e dos fatos, e as forças sociais que os produzem" (FRIGOTTO, 2011, p. 237). 
Com isso, a Lei que o aprova define importantes diretrizes que expressam as reivindicações da sociedade brasileira: erradicação do analfabetismo; universalização do atendimento escolar; melhoria da qualidade da educação; valorização dos (as) profissionais da educação; promoção do princípio da gestão democrática da educação pública; promoção dos princípios do respeito aos direitos humanos, à diversidade e à sustentabilidade socioambiental (BRASIL, 2014).

Como resultado da construção coletiva na Conferência Nacional de Educação (CONAE), do debate na tramitação do projeto no Congresso Nacional e dos consensos histori- camente possíveis, o PNE é compreendido como o "epicentro' das políticas educacionais, "pois ele constituiu o eixo central das políticas educacionais e, portanto, uma efetiva política de Estado para a educação", conforme análise de Dourado $(2017,17)$.

Segundo o art. 8ำ da Lei $\mathrm{n}^{0} 13.005$ de 2014, os Estados, o Distrito Federal e os Muni- cípios deverão elaborar seus correspondentes planos de educação, ou adequar os planos já aprovados em lei, em consonância com as diretrizes, metas e estratégias previstas neste PNE, definindo o prazo de 1 (um) ano contado da publicação desta lei (BRASIL, 2014).

Assim, a União, os estados, o Distrito Federal e os municípios devem se organizar para alcançar as metas e as estratégias de curto, médio e longo prazo até 2024. 0 cumprimento das metas e estratégias do Plano, portanto, "[...] está diretamente relacionado à vigilância e controle social, que neste caso parecem ser de uma dimensão poucas vezes (ou nunca) vista na história educacional brasileira" (SOUZA, 2016, p. 118).

Ao ser aprovado em 2014, os principais desafios do PNE, como eixo das políticas educacionais, referem-se ao processo de materialização do plano, que "[...] se efetiva na intersecção entre regulamentação, regulação e ação política, marcados por disputas que traduzem os embates históricos entre as classes sociais e, ao mesmo tempo, os limites estruturais que demarcam as relações sociais capitalistas" (DOURADO, 2017, p. 46).

Com base nessas considerações, este artigo analisa o processo de materialização do Plano Estadual de Educação de Mato Grosso do Sul (PEE/MS), como política pública, de modo a apreender as condições objetivas desse processo, as concepções em disputa acerca da gestão educacional, e, sobretudo, a regulamentação da gestão democrática da educação, princípio constitucional, em consonância com o art. 9º do PNE (BRASIL, 2014).

Parte-se do pressuposto de que,

A educação, quando apreendida no plano das determinações sociais e, portanto, ela mesma constituída e constituinte destas relações, apresenta-se historicamente como um campo da disputa hegemônica. Esta disputa dá-se na perspectiva de articular as concepções, a organização dos processos e dos conteúdos educativos na escola e, mais amplamente, nas diferentes esferas da vida social, aos interesses de classe (FRIGOTTO, 1995, p. 25).

\footnotetext{
2 Com o golpe jurídico-midiático-parlamentar, de 2016, que depôs a Presidente eleita Dilma Rousseff e instituiu como Presidente o então vice Michel Temer, em 26 de abril de 2017, um Decreto do Executivo, revogou a convocatória da III Conferência Nacional de Educação a ser realizada em 2018, restringindo o papel do Fórum na articulação e coordenação da Conferência. Ainda, a Portaria no 577, de 27 de abril de 2017, alterou a composição do Fórum, reduzindo a participação da sociedade civil. Em decorrência, 20 entidades renunciaram, criando, na sequência, o Fórum Nacional Popular de Educação (FNPE) (DOURADO, 2018).
} 
A análise desse processo busca explicitar o movimento do real no contexto social em que se insere, e, portanto, a disputa de concepções de gestão educacional, que se materializa de diferentes formas. Para tanto, utiliza a análise bibliográfica, documental e entrevistas semiestruturadas, com representantes da sociedade política e da sociedade civil do estado de Mato Grosso do Sul.

\section{O PEE/MS E O PRINCÍPIO CONSTITUCIONAL DA GESTÃO DEMOCRÁTICA}

O Plano Estadual de Educação (PEE/MS) de Mato Grosso do Sul ${ }^{3}$, foi aprovado pela Lei oㅜ 4.621 de 22 de dezembro de 2014, com 20 metas e estratégias, no segundo mandato do governo de André Puccinelli (2011-2014), do Partido do Movimento Democrático Brasileiro (PMDB), atual Movimento Democrático Brasileiro (MDB).

Do ponto de vista da metodologia de trabalho, conforme consta nas "Considerações iniciais" apresentadas, o Texto Base, a partir da elaboração em seis oficinas, de 23 de agosto a 3 de setembro de 2014, e da formação continuada denominada "PEE nas Escolas", coordenada pela Secretaria de Estado de Educação, abrangendo no total 22 mil pessoas, cadastradas no Sistema PEE-MS, foi debatido nos 10 Seminários Regionais de Mato Grosso do Sul e aprovado no "Seminário Estadual de Educação: construindo coleti- vamente o Plano Estadual de Educação (PEE-MS 20142024)", realizado nos dias 15 e 16 de setembro de 2014, em um processo coordenado pelo Fórum Estadual de Educação de Mato Grosso do Sul (FEEMS) (MATO GROSSO DO SUL, 2014).

Destacam-se no percurso histórico de construção coletiva do PEE/MS, os seguintes eventos:

I Conferência Nacional de Educação Básica, em 2008, que culminou com a promulgação da Emenda Constitucional $n^{0}$ 59/2009, que amplia a escolarização obrigatória- de 4 a 17 anos;

I Conferência Estadual de Educação em 2009. A Comissão Estadual Organizadora, em parceria com as comissões municipais, realizou 23 conferências municipais e intermunicipais, envolveu cerca de 3.000 participantes entre educadores, pais, alunos, setores, da sociedade civil organizada e representantes dos movimentos sociais. Essas Conferências foram preparatórias para a Conferência Nacional de Educação de 2010;

I Conferência Nacional de Educação - CONAE 2010, que embasou a elaboração do atual Plano Nacional de Educação (PNE), Lei no 13.005/2014;

II Conferência Estadual de Educação, em 2013. O Fórum Estadual de Educação (FEEMS), juntamente com os fóruns municipais de educação e comissões organizadoras, realizou, nos municípios, 79 Conferências Livres e 17 Conferências Intermunicipais de Educação, com a participação de educadores, gestores e representantes das instituições da sociedade civil organizada, bem como representantes dos movimentos sociais, envolvendo, 13.000 pessoas. Essas conferências foram preparatórias para a II CONAE 2014 (MATO GROSSO DO SUL, 2014, p. 10).

3 O Estado de Mato Grosso do Sul foi criado a partir da divisão do Estado de Mato Grosso, no governo do presidente Ernesto Geisel (1974-1979), por meio da Lei Complementar oㅡ 31, de 11 de outubro de 1977. A instalação do Governo Estadual de MS ocorreu em primeiro de janeiro de 1979. Situa-se na Região Centro- Oeste e faz fronteira, a sudoeste, com as Repúblicas do Paraguai e da Bolívia; a Sudeste, com os Estados de Minas Gerais e São Paulo; ao Sul, com o Paraná; e, ao norte, com Mato Grosso e Goiás. Possui 79 municípios distribuídos em área de 357.145,534 Km2. Disponível em: https://www.ibge.gov.br/cidades-e- estados/ms.html. Acesso em: 10 set. 2020. 
Tal participação é compreendida em articulação ao movimento nacional de elaboração do PNE 2014-2024, mediada pelo Estado (aparelho governamental) e com ampla participação dos segmentos da sociedade civil, especialmente, nas Conferências Nacionais de Educação, como mostra o texto do PEE/MS, marcada por uma conjuntura favorável à participação dos interessados em sua elaboração e na sua materialização.

Como assinala Cury (2013),

Não é só dos funcionários do Estado, não é só dos parlamentares que nascem as responsabilidades do plano. A identificação de problemas, de caminhos, de como percorrer os caminhos, a enunciação de valores comuns envolve os que fazem a educação de cada dia e disso atestam a Conferência Nacional de Educação 2010 e o Fórum Nacional de Educação. (CURY, 2013, p. 32).

Esses mecanismos e instrumentos de participação vinculam-se ao processo recente de abertura democrática no País, de consolidação de instituições republicanas e de alargamento da participação de novos sujeitos, individuais e coletivos, sobretudo, a partir da promulgação da Constituição Federal de 1988, portanto, há 32 anos.

A CF de 1988, ao definir, em seu art. 206, os princípios da educação escolar, entre eles, o inciso VI indica a "gestão democrática do ensino público, na forma da lei". Este princípio constitucional, inédito, fundamenta-se na noção de Estado Democrático de Direito, tal como expresso na Constituição Federal ${ }^{4}$, que implica a soberania popular e impõe algo mais que o voto universal, o voto para todas as pessoas, isto é, o controle social da administração pública (VIEIRA, 2001), assim, "reconhece e inclui o poder popular como fonte do poder e da legitimidade e o considera como componente dos processos decisórios mais amplos de deliberação pública e de democratização do próprio Estado". (CURY, 2002, p. 172).

A Lei de Diretrizes e Bases da Educação Nacional (LDBEN), Lei no 9.394, de 20 de dezembro de 1996, reafirma os princípios do ensino, atribuindo no art. $3^{\circ}$, Inciso VIII, "gestão democrática do ensino público, na forma desta Lei e da legislação dos sistemas de ensino" (BRASIL, 1996). Com isso, delegou aos sistemas de ensino a prerrogativa de sua construção e operacionalização, desde que atendidos os dois incisos especificados no art. 14, quer dizer,

Os sistemas de ensino definirão as normas da gestão democrática do ensino público na educação básica, de acordo com as suas peculiaridades e conforme os seguintes princípios:

I- participação dos profissionais da educação na elaboração do projeto pedagógico da escola;

II - participação das comunidades escolar e local em conselhos escolares ou equivalentes (BRASIL, 1996).

É importante notar que essa participação acontece em duas condições, uma interna à escola, com a ação dos profissionais da educação na elaboração do projeto pedagógico da escola e, outra, externa, na medida em que inclui a presença de pessoas da comunida de local na qual a escola está inserida na composição e funcionamento, por exemplo, dos conselhos escolares (SOUZA, 2016).

O PEE/MS, em concordância com o PNE 2014-2024, define, entre as suas diretrizes, 
a promoção do princípio da gestão democrática da educação pública, embora tal princípio tenha ficado restrito à educação pública.

\section{O PEE/MS E A NORMATIZAÇÃO DA GESTÃO DEMOCRÁTICA}

A Lei estadual n 4.621 , de 2014, também em consonância com o art. $9^{\circ}$ da Lei 13.005, de 2014, orienta, no art. 10, que os estados e municípios, no âmbito de suas competências, "deverão aprovar lei específica para os seus sistemas de ensino, disciplinando a gestão democrática da educação pública”, no prazo de dois anos, contado da publicação do PNE (MATO GROSSO DO SUL, 2014).

De acordo com o relatório da Comissão de Monitoramento e Avaliação do PEE/MS (CMAPEEMS) $^{5}$, a Gestão Democrática da Rede Estadual de Ensino de Mato Grosso do Sul está regulamentada pela Lei no 2.787, de 24 de dezembro de 2003 (MATO GROSSO DO SUL, 2003), que dispõe sobre o Sistema Estadual de Ensino de Mato Grosso do Sul. Sintetiza que nessa lei,

[...] a concepção de gestão democrática é entendida como princípio e prática político-filosófica e como ação coletiva, norteia todas as ações de planejamento, formulação, implementação e avaliação das políticas educacionais e alcança todas as entidades e organismos integrantes do Sistema Estadual de Ensino. Nesta, também constam os princípios da gestão democrática: transparência, respeito e autonomia (MATO GROSSO DO SUL, 2018, p. 99).

A lei supracitada, ao conceber a gestão democrática, no art. 36, como princípio e prática político-filosófica, destaca a ação coletiva como elemento norteador da gestão do Sistema Estadual de Ensino. Pode-se entender que a participação é instituída como componente básico, assentada nos princípios da gestão democrática, assim definidos: "transparência nos mecanismos pedagógicos, administrativos e financeiros; respeito à organização dos segmentos da comunidade escolar; e autonomia político-pedagógica e administrativa". (MATO GROSSO DO SUL, 2004, p. 16-17).

Considera-se que esses princípios são pertinentes aos propósitos da gestão democrática, principalmente ao explicitar que ela será efetivada mediante participação da comunidade escolar na:

\footnotetext{
elaboração do Plano Estadual de Educação com efetiva participação da sociedade sul-mato-grossense;

I - elaboração e aprovação da proposta pedagógica do regimento escolar pelas instituições de ensino;
}

\footnotetext{
5 A Comissão foi constituída, incialmente, pelas seguintes instâncias: Secretaria de Estado de Educação (SED-MS); Comissão de Educação da Assembleia Legislativa; Conselho Estadual de Educação de Mato Grosso do Sul (CEE-MS); Fórum Estadual de Educação de Mato Grosso do Sul (FEEMS) (MATO GROSSO DO SUL, 2015a). Esta comissão foi ampliada pelo Decreto no 14.281/2015, com representantes das seguintes entidades: Tribunal de Contas do Estado (TCE); Instituição de Educação Superior Pública; Sindicato dos Estabelecimentos de Ensino de Mato Grosso do Sul (SINEPE/MS); Federação dos Trabalhadores em Educa- ção de Mato Grosso do Sul (FETEMS); União Nacional dos Conselhos Municipais de Educação (UNCME); e União Nacional dos Dirigentes Municipais de Educação (UNDIME) (MATO GROSSO DO SUL, 2015b).
} 
Plano Estadual de Educação de Mato Grosso do Sul...

II - avaliação da aprendizagem dos educandos, do desempenho dos profissionais da educação e da instituição;

III - indicação dos diretores, nas escolas públicas, com participação efetiva da comunidade escolar, adotado o sistema eletivo, mediante voto direto proporcional e secreto na forma da lei ou regulamento próprio (MATO GROSSO DO SUL, 2004, p.16-17).

Esse argumento se justifica face à compreensão de que,

A gestão democrática é parte do projeto de construção de democratização da sociedade brasileira. Nesse sentido, a construção do projeto político-pedagógico, a participação em conselhos, a eleição para diretores, a autonomia financeira, são processos pedagógicos de aprendizagem da democracia, tanto para a comunidade escolar, quanto para a comunidade em geral, porque a participação, depois de muitos e muitos anos de ditadura, é um longo processo de construção (PERONI, p. 2012, p. 26).

Ainda, a Lei acrescenta a esses princípios, em seu art. 39, as estratégias para assegurar a gestão democrática,

I - a descentralização do processo educacional;

II - a adoção de mecanismos que garantam a precisão, segurança e confiabilidade nos procedimentos de registros de atos relativos à vida escolar, nos aspectos pedagógicos, administrativos, contábil e financeiro, de forma a permitir a eficácia da participação da comunidade escolar, diretamente interessada no funcionamento da instituição de ensino;

III - o funcionamento, no âmbito dos órgãos executivo e normativo do Sistema Estadual de Ensino, do Fórum Estadual de Educação, com a participação de represen- tantes das entidades dos diversos segmentos da sociedade educacional do Estado; IV - a garantia, em cada instituição pública de educação básica, de:

a) colegiados escolares, com a participação de representantes da comunidade escolar, definidos em regulamento próprio;

b) critérios democráticos para escolha de diretor da escola;

c) transferência automática e sistemática de recursos às unidades escolares, na forma definida em lei ou regulamento próprio (MATO GROSSO DO SUL, 2004, p. 17).

Ressalta-se, entre as estratégias, a importância atribuída ao Fórum Estadual de Educação de Mato Grosso do Sul (FEEMS), com a participação de representantes das entidades dos diversos segmentos da sociedade educacional do Estado.

O entrevistado do FEEMS, ao responder sobre o processo de materialização do PEE/MS, afirma que esse Fórum tem "o objetivo de acompanhar essa implementação e vamos dizer assim até fiscalizar o que está acontecendo, porque, o Fórum também está sendo cobrado pelo Tribunal de Contas e outros órgãos que nos questionam sobre a implementação deste plano". Acrescenta que,

E nós temos a parceria com o estado, a Secretaria de Estado de Educação, porque foi criado dentro do Fórum, o Observatório para acompanhar esse processo e este Observatório, ele hoje é conduzido por um representante da Secretaria que está participando do Fórum também, e ele é o coordenador e estava coordenador e foi reconduzido [...]. Até final de 2018, nós tínhamos mais dados, estavam sendo mais sistematizadas essas informações. Já no ano de 2019, eu vejo que essa análise, ela se perdeu um pouco (REPRESENTANTE FEEMS, ENTREVISTA, 07/02/2020).

6 Conforme o art. 1o, parágrafo único, da CF de 1988, "Todo o poder emana do povo, que o exerce por meio de representantes eleitos ou diretamente, nos termos desta Constituição” (BRASIL, 1988). 
Conforme assinala o entrevistado, pode-se verificar a presença ativa do Fórum Estadual de Educação, com a participação do GT Observatório ${ }^{6}$ e Grupos de Trabalho Permanentes (GTPs), na Comissão que elaborou o relatório denominado " $1{ }^{\circ}$ Relatório de Monitoramento e Avaliação do Plano Estadual de Educação: Sistematização das metas Estratégicas", por meio de "ações conjuntas para a sistematização do monitoramento do PEE/ MS" (CMAPEEMS, 2017, p.7-8).

No relatório correspondente ao ciclo 2015/2016, a Comissão informa que reúne informações referentes à execução das estratégias e ao cumprimento das metas do PEE/MS, com o apoio da Equipe técnica da Secretaria de Estado de Educação e que concentrou a análise nos dados disponibilizados nos portais eletrônicos, especificamente, das seguintes instituições: Observatório do PNE; Instituto Nacional de Pesquisas e Estatística Anísio Tei- xeira (INEP); Instituto Brasileiro de Geografia e Estatística (IBGE); bem como no Anuário Brasileiro da Educação Básica, produzido pela Associação Todos Pela Educação (MATO GROSSO DO SUL, 2018).

Segundo os entrevistados,

\begin{abstract}
Esse trabalho da Equipe técnica, nós definimos a partir da Comissão que seria um trabalho mais operacional de coleta dos dados, então, quando do monitoramento, a gente precisava fazer a coleta dos dados para a analise do cumprimento da meta e da execução das estratégias então essa equipe técnica ela ia desbravar as fontes oficiais para encontrar esses dados (REPRESENTANTE SED/MS, ENTREVISTA, 09/01/2020).

A Secretaria de Estado de Educação conta com uma Equipe Técnica que assessora e contribui com os trabalhos da CMAPEE. Não tenho conhecimento de que tenha outros instrumentos ou recursos voltados para o cumprimento das metas do PEE (REPRESENTANTE DA ALE/MS, ENTREVISTA, 17/12/2019).
\end{abstract}

Pode-se inferir que a Secretaria de Estado de Educação de MS assumiu a centralidade na condução do processo, observando-se que o relatório não menciona a participa- ção do GT Observatório do FEEMS no decorrer do processo de monitoramento e avaliação no período.

O relatório da CMAPEEMS refere-se, também, aos mecanismos de efetivação da Gestão Democrática definidos pela Lei n².787, de 24 de dezembro de 2003, ou seja,

[...] o Projeto Político Pedagógico (PPP), a eleição para escolha de diretor e diretor adjunto e eleição para constituição de Colegiados Escolares, formando assim uma Gestão Colegiada e a descentralização do processo educacional nas escolas da rede estadual. Na gestão financeira, a Associação de Pais e Mestres (APM) é a Unidade Executora dos recursos financeiros recebidos pela unidade escolar, onde a mesma é constituída e gerida por um Estatuto próprio, compondo assim a estrutura da Gestão Democrática (MATO GROSSO DO SUL, 2018, p. 98-99).

7 O GT Observatório, criado em 2015, previsto no regimento do FEEMS, com a finalidade de "estruturar uma equipe para desenvolver ações com vistas à coleta e análise de dados referentes à execução do PEE-MS, bem como para subsidiar a Comissão de Monitoramento e Avaliação do Plano Estadual de Educação", realizou dezesseis reuniões no período de 2015 a 2016 para discutir a metodologia de trabalho de acompa- nhamento do Plano Estadual de Educação, sob a orientação de professores especialistas na área (CMA- PEEMS, 2017, p. 7-12). 
Em decorrência, assevera que a Secretaria de Estado de Educação, "respeitando a legislação em vigor promove a escolha dos diretores com a participação efetiva da comunidade escolar, por meio de eleição, voto direto e secreto, bem como a escolha dos membros que compõem o Colegiado Escolar" (MATO GROSSO DO SUL, 2018, p. 99).

Esse processo é relatado pelo representante da Secretaria de Estado de Educação (SED) de Mato Grosso do Sul, entrevistado,

Hoje a Secretaria de Estado de Educação institui um processo no qual os professoes da Rede, das escolas da Rede, se submetem para alcançar a função de gestor escolar. Primeiramente ele é submetido a uma avaliação para uma análise do nível de conhecimento desse professor, a respeito do perfil, do papel do gestor escolar, então ele é submetido a uma avaliação, aqueles que são aprovados na avaliação, compõem um banco e somente o professor que consta nesse banco pode partici- par do processo de eleição que ocorre após a composição do banco. E sempre é oportunizado mais de um profissional da escola, a participar desse processo, então é feito um cálculo de quantos professores da escola podem participar. Minimamen- te, todos os professores têm oportunidade, mas apenas um conjunto, parte deles que vai participar do processo, e quando o banco é constituído inicia-se o processo eleitoral, com todos os procedimentos a serem seguidos, e o professor que está nesse banco, ele participa desse processo, mas é a comunidade que elege, mas a comunidade já realiza eleição sabendo que aquele professor que colocou o nome para apreciação, minimamente, já passou por um processo de análise de conhecimento, de competências, de habilidades, para poder exercer a função que é aquilo que, minimamente, a meta [Meta 19 do $\mathrm{PEE} / \mathrm{MS}$ ] propõe, uma análise de mérito e a consulta à população, à comunidade escolar [...]. (REPRESENTANTE SED/MS, ENTREVISTA, 09/12/2020).

A modalidade de seleção que combina a aplicação de avaliação de competências básicas, mediante prova escrita aos candidatos a diretores escolares, seguida de eleição, na Rede Estadual de Ensino de Mato Grosso do Sul, contrapõe-se à escolha por meio de eleição direta, conforme se verifica na Lei do Sistema Estadual de Ensino, como um dos mecanismos de gestão democrática, e, ainda, a constituição de um "Banco" de candidatos aprovados na avaliação.

O relatório da CMAPEEMS acentua que na Rede Estadual de Ensino de MS,

[...] todas as escolas passaram pelo processo de seleção, que inclui curso de gestão, avaliação de competências básicas e eleição. Nesta última etapa, somente algumas instituições, como: os Centros de Educação Profissional, o Centro Estadual de Formação de Professores Indígenas de MS, os Centros de Educação de Jovens e Adultos, o Centro de Educação Infantil e as escolas conveniadas, não realizaram a eleição, mas participaram de todas as demais etapas do processo (MATO GROS- SO DO SUL, 2018, p. 99).

Questiona-se essa ação, na medida em que a avaliação de competências básicas é destinada a todas as escolas, mesmo que, em algumas delas, a eleição tenha sido excluída do processo. Infere-se que "Quando a gestão democrática da educação se associa à meritocracia, espaços de decisão coletivas são deslegitimados em razão do mérito individual" (FERNANDES, 2018, p. 101).

O representante da Assembleia Legislativa de MS, entrevistado, expõe que,

Entendo que o Estado de Mato Grosso do Sul não regulamentou, por meio de lei específica, a gestão democrática no âmbito do seu sistema de ensino. O Estado possui apenas legislação que disciplina o processo democrático para a escolha dos dirigentes e colegiados escolares. Este processo foi implantado por decreto no governo Pedro Pedrossian. Em 2006, a Assembleia Legislativa aprovou lei 
estadual, de iniciativa do deputado Pedro Kemp, disciplinando a matéria, que sofreu altera- ções nos governos André Puccinelli e Reinaldo Azambuja. Principalmente a última alteração, em 2019, foi realizada no sentido de restringir a participação da comu- nidade escolar na escolha dos dirigentes escolares, estabelecendo provas para os candidatos, excluindo professores contratados como eleitores, e deixando as esco- las de tempo integral e escolas indígenas de fora do processo. (REPRESENTANTE DA ALE/MS, ENTREVISTA, 17/12/2019).

Como se observa, o entrevistado crítica as alterações no processo de escolha dos diretores escolares, na medida em que a Lei 3.479, de 6 de dezembro de 2007, revogou a Lei no 3.244, de 6 de junho de 2006, aprovada no segundo mandato do governo José Orcírio Miranda dos Santos (2003-2006), do Partido dos Trabalhadores (PT), que regulamentou para a Rede Estadual de Ensino a eleição para diretor e diretor- adjunto pela comunidade escolar, por meio do voto direto, secreto e proporcional, assim como a escolha do colegiado escolar, constituído por representantes de todos os segmentos que compõem a comunida- de escolar (MATO GROSSO DO SUL, 2006).

A Lei $n^{\circ} 3.479$, de 6 de dezembro de 2007, aprovada na gestão do governo André Pucinelli (2007-2010), do PMDB, à época, define as normas para a eleição de diretores escolares da Rede Estadual de Ensino de MS, porém, o processo deixou de ser por eleição direta e passou a ser seletivo (Art. $1^{\circ}$ ), em três etapas: I. curso de capacitação em Gestão Escolar; II. Avaliação de competências básicas de dirigente escolar; III. Eleição (MATO GROSSO DO SUL, 2007).

Alguns dispositivos dessa lei foram modificados no Governo de Reinaldo Azambuja (2015-2018), do PSDB. Entre as modificações, no art. 5º de que ficam dispensadas da realização de eleições para diretor e para diretor-adjunto as unidades escolares conveniadas; as unidades escolares responsáveis pelo atendimento aos alunos de Unidades Educacionais de Internação (UNEIs) e presídios; os centros de educação infantil; o centro estadual de formação de professores indígenas; os centros de educação profissional e os centros de educação de jovens e adultos, conforme redação dada pela Lei $n^{\circ}$ 4.696, de 15 de julho de 2015 (MATO GROSSO DO SUL, 2015c).

O Edital SED/MS [Secretaria de Estado de Educação de Mato Grosso do Sul] n 19 , de 12 de setembro de 2019, expressa essa intenção ao definir que "A Avaliação de Competências Básicas de Dirigente Escolar é requisito preliminar necessário para que os profissionais da educação possam ser designados para a função de Diretor e de Diretor Adjunto" (MATO GROSSO DO SUL, 2019a, p. 37).

Expõe, ainda, que

A avaliação tem por objetivo aferir os conhecimentos dos profissionais da educação nas competências necessárias para o desempenho da função de dirigente escolar e consistirá na submissão dos interessados à realização de prova de conhecimentos específicos, cujas referências bibliográficas constam do Anexo Único deste Edital. Os profissionais da educação que obtiverem êxito na Avaliação de Competências constituirão um Cadastro de Profissionais Aptos na Avaliação de Competências Básicas de Dirigente Escolar, por município, para participarem do processo de escolha e indicação pela comunidade escolar para a função de Diretor ou Diretor Adjunto de escola estadual. (MATO GROSSO DO SUL, 2019a, p. 37).

Como deixa claro o Edital, a ênfase está no mérito para a escolha de "dirigentes 
escolares", por meio de uma prova escrita, composta por 25 questões de múltipla escolha sobre temas específicos e restrita a determinadas habilidades, como: procedimentos de Leitura de textos na área da Educação; habilidades básicas em Matemática; avaliações educacionais; indicadores educacionais (acesso, permanência, rendimento escolar, distorção idade/ano, proficiência, fluxo escolar e IDEB); gestão escolar (Pedagógica, Administrativa e Financeira); e Legislação Educacional. (MATO GROSSO DO SUL, 2019a).

Entre as atribuições de "Dirigente Escolar" (item 3.1.do Edital), está a de que deve "cumprir as metas estabelecidas para a escola, conforme consta do Termo de Compromisso assinado quando da posse". (MATO GROSSO DO SUL, 2019a).

Salienta-se que o responsável pela aplicação da Avaliação de Competências Básicas de Dirigente Escolar é o Centro de Políticas Públicas e Avaliação da Educação $(\mathrm{CAEd})^{7}$ (MATO GROSSO DO SUL, 2019, p. 37). Com isso, observa-se que a Secretaria de Estado de Educação transfere o processo avaliativo a uma instituição privada, sem fins lucrativos. Isso se explica, utilizando a análise de Oliveira (2015), em certa medida,

[...] pela grande aderência dos gestores municipais e estaduais a essa lógica de mensuração, que põe a técnica no lugar da política e a eficiência no lugar da ampliação do bem-estar como um direito. Se explica ainda, pelo fato de que a avaliação se tornou um grande negócio que envolve importantes cifras monetárias e que repre- senta um campo de interesses direto ou indireto em que especialistas e empresas de consultorias, ONG, Institutos Empresariais, entre outros, envolvemse nas políticas de Estado para disputar recursos públicos para seus fins privados. (OLIVEIRA, 2015, p. 642).

Outra alteração a ser considerada, refere-se à Lei 5.466, de 18 de dezembro de 2019, que dispõe sobre a "Gestão Democrática do Ensino e Aprendizagem" e sobre o processo de seleção dos dirigentes escolares e dos membros do Colegiado Escolar, no âmbito da Rede Estadual de Ensino, aprovada no segundo mandato do governo de Reinaldo Azambuja, do PSDB, que teve inicio em $1^{\circ}$ de janeiro de 2019.

Conforme o seu art. 10 "A Gestão Democrática do Ensino e Aprendizagem Públicos, princípio inscrito no art. 206, inciso VI, da Constituição Federal, no art. 189, inciso VI, da Constituição Estadual, e no art. 3ำ, inciso VI, da Lei Estadual ํㅜㄴ.787, de 24 de dezembro de 2003", será exercida com observância aos seguintes preceitos:

\footnotetext{
I - transparência nos mecanismos pedagógicos, administrativos e financeiros;

II - respeito à organização dos segmentos da comunidade escolar;

III - autonomia político-pedagógica e administrativa;

IV - participação dos profissionais da educação, estudantes e pais na formulação do Projeto Político-Pedagógico da escola, do Currículo Escolar, do Plano de Gestão Escolar e do Regimento Escolar;

$\mathrm{V}$ - participação dos pais na avaliação dos docentes e gestores escolares;

VI - participação dos segmentos da comunidade escolar nos processos decisórios e em órgãos colegiados.

VII - garantia da descentralização do processo educacional;

VIII - valorização dos profissionais da educação;

IX - desenvolvimento de programas de formação de gestores escolares. (MATO GROSSO DO SUL, 2019b).
}

Como se verifica, a lei focaliza a gestão democrática no âmbito escolar, destacandose o Colegiado Escolar, como órgão integrante da estrutura das escolas da Rede Estadual 
de Ensino (art. $6^{\circ}$ ), sendo que seus membros serão escolhidos pela escola, dentre os segmentos de estudantes, pais, professores, coordenadores pedagógicos, funcionários técnico-administrativos para mando de 4 (quatro) anos, admitida uma recondução, em processo a ser regulamentado pela SED/MS (Art. $8^{\circ}$ ).

Como conselho presente nas escolas da rede estadual de ensino, o representante da SED/MS argumenta que o colegiado escolar,

Ele tem a representação do segmento estudante, ele tem a representação do segmento professor, ele é uma instituição composta por representações. O colegiado, na minha opinião, ele ainda é um segmento, ele é uma instituição dentro da escola que ainda necessita de um fortalecimento, de uma ação pensada exclusivamente para esse órgão, ali dentro, para o [seu] fortalecimento. Mas ele não apresenta a mesma fragilidade que a APM [Associação de Pais e Mestres] apresentava. Porque a APM existia na pessoa de um pai na escola e o colegiado, não, ele pela força das questões que muitas vezes a gestão não consegue ou não tem competência para poder gerir sozinha, esse colegiado ele é solicitado [...].

Então o colegiado ele é mais atuante que a própria APM dentro da escola, mas começamos a atacar aquele segmento que tinha menos representação, menos atuação para fortalecer, então eu acho que é um processo e, nesse processo, o colegiado será contemplado. Ainda não foi contemplado com uma ação pontual exclusiva para esse segmento, mas que certamente será alcançado. Eu não conseguiria hoje exemplificar uma ação mais direcionada ao colegiado, mas que não quer dizer que não exista, talvez, numa conversa com a coordenadora de gestão escolar ela consiga apresentar o exemplo de uma ação pontual junto ao colegiado. (REPRESENTANTE SED/MS, ENTREVISTA, 09/01/2020).

Em seu relato admite a importância do colegiado escolar na rede estadual de ensino, entretanto, mostra a necessidade de ações por parte da Secretaria de Estado de Educação para o seu fortalecimento. Isso remete à análise de Lima (2014) de que a colegialidade é a dimensão mais próxima de concepções democráticas de caráter participativo, um elemento teoricamente superior à liderança unipessoal, monocrática não letiva, eventualmente autocrática, quando centralizada na figura de um diretor.

A escolha de diretores escolares na Lei $n^{\circ}$ 5.466, de 18 de dezembro de 2019, segue as mesmas etapas definidas em leis anteriores, sendo decisiva a Avaliação de Competências Básicas de Dirigente Escolar, constituída em prova de conhecimentos, para participar de eleição pela comunidade escolar (Art. 16) (MATO GROSSO DO SUL, 2019b, p. 10).

Além disso, o exercício da função, conforme o art. 29,

[...] dependerá de assinatura de Termo de Compromisso, no qual o designado se compromete a cumprir os deveres da função, as orientações técnicas da SED/MS, a política pública definida para a educação do Estado, as metas estabelecidas pela escola, o Projeto Político-Pedagógico, o Plano de Gestão Escolar, bem como o Estatuto dos Profissionais da Educação Básica do Estado, o Estatuto dos Servidores Públicos Civis do Estado, no que couber, as leis específicas acerca da educação e as Constituições Federal e Estadual.

8 "A Fundação Centro de Políticas Públicas e Avaliação da Educação (Fundação CAEd) é uma fundação de apoio à Universidade Federal de Juiz de Fora (UFJF), devidamente credenciada junto ao MEC/MCTI, sendo constituída como entidade privada, sem fins lucrativos, destinada a prestar apoio especializado à execução de projetos e serviços relacionados à avaliação educacional em larga escala e ao desenvolvimento de tecnologias de avaliação e gestão da educação pública". Disponível em: http://fundacaocaed.org.br/\#!/fundacao. Acesso em: 8 out. 2020. 
$\S 1^{0}$ As metas estabelecidas no Termo de Compromisso serão objeto de avaliação periódica para verificação dos seus resultados, avanços e/ou pactuação de novas metas de melhorias da qualidade de ensino e da aprendizagem.

$\S 2^{0}$ É obrigatória a participação dos designados para as funções de Diretor e de Diretor Adjunto no Curso de Formação em Gestão Escolar, sob pena de revogação da designação, e nos demais cursos de formação continuada a serem oferecidos pela SED/MS ou por parceiros conveniados, conforme dispuser o regulamento. (MATO GROSSO DO SUL, 2019, p.12).

A lógica "eficientista", como sintetiza Oliveira (2015, p. 642), justifica-se por critérios de justiça baseados no mérito individual, "que repousa sobre uma perspectiva homogênea e padronizada de avaliação para fundamentar uma distribuição diferenciada".

Alie-se a isso o fato de que, conforme o art. 31, outras instituições ficaram dispensadas da realização de eleição para escolha de "Dirigentes Escolares", como as escolas indígenas, as escolas de educação de tempo integral, as escolas cívico-militares, os centros de formação de docentes e de apoio educacional da SED/MS (MATO GROSSO DO SUL, 2019b, p. 13).

Considera-se a eleição uma das dimensões da gestão democrática, que, se associada às dimensões participação colegiada nas decisões e autonomia das escolas, pode dar sentido a espaços e tempos organizacionais, individuais e coletivos, de diálogo e deliberação (AFONSO, 2010).

Essas dimensões representam, portanto, os elementos mais importantes da gestão democrática, entendendo-se que,

A democracia não constitui um estágio, ela constitui um processo. O processo pelo qual a soberania popular vai controlando e aumentando os direitos e os deveres é um processo prolongado, implicando avanço muito grande dentro da sociedade. Quanto mais coletiva é a decisão, mais democrática ela é. Qualquer conceito de democracia, aliás há vários deles, importa em grau crescente de coletivização das decisões. Quanto mais o interesse geral envolve um conjunto de decisões, mais democráticas elas são. (VIEIRA, 2001, p. 14).

O que importa reter, aqui, ao fazer referência, entre outras, às modificações na legislação sobre a forma de provimento do cargo de diretor escolar, é a concepção de gestão que sustenta essas ações e que pelo seu conteúdo, como a introdução de avaliação indi- vidual de competências básicas para diretores escolares, inserem-se em uma estratégia mais ampla para colocar em prática reformas políticas e administrativas que passou a ser referida como Nova Gestão Pública (NGP) ${ }^{8}$. Do ponto de vista da NGP, o Estado deve fortalecer o seu papel de regulador, avaliador e distribuidor de incentivos aos provedores autônomos desses serviços, em vez de prover serviços públicos diretamente (VERGER; NORMAND, 2015).

Apesar de, ao longo do século XX, terem sido produzidas diferentes ondas de reformas na gestão do setor público, esse modelo, de acordo com Verger e Normand (2015), começou a ser inserido nos países industrializados ocidentais, na década 1980. No Bra- sil, como já mencionado, sua inserção ocorreu nos anos 1990, tendo como referência o PDRAE, em que a administração pública gerencial é apresentada como solução para os problemas de clientelismo, burocratismo e patrimonialismo, assim como 
obedece a critérios gerenciais de eficiência. Nele encontram-se os elementos centrais para o chamamento das parceiras público-privadas (PERONI: OLIVEIRA, FERNANDES, 2009).

A NGP considera a gestão privada de tipo empresarial mais racional, eficaz e eficiente, "como regeneradora da administração pública, cujo caráter burocrático seria imanente, e como capaz de vencer as resistências à mudança, que seriam típicas do corporativismo dos seus profissionais". Ao assumir uma orientação com base em critérios técnicos e racio- nais, defende modelos de governação e técnicas de gestão que garantam o alcance dos mais elevados padrões de eficácia e eficiência, de competitividade e atratividade, de inova- ção e diferenciação das escolas (LIMA, 2013, p. 66).

Nesse sentido, algumas características-chave representam as propostas da NGP no setor público: criação de normas - padrão, e medidas de desempenho explícitas para as unidades que prestam serviços; necessidade de estabelecer relações claras entre inputs, outputs, e medidas de desempenho, com ênfase no controle dos resultados; crescentes exigências de responsabilização ou prestação de contas; valorização de estilos de gestão do setor privado; promoção da competição entre diferentes unidades; e disciplina e austeridade na utilização de recursos (AFONSO, 2002).

No entanto, como assinala Verger e Normand (2015), a NGP, como qualquer outro modelo de reforma educativa global, não foi recebida e adaptada de forma homogênea nos distintos lugares em que se inseriu. Embora as reformas globais na educação apresentem características comuns, as políticas em que acabam resultando são mediadas por fatores históricos, políticos-administrativos e culturais, assim como pelas forças e realidades locais.

No campo da educação, acentua o autor, nos lugares, países e regiões, em que foi aplicada, a NGP, no entanto, alterou a forma como a gestão das instituições educativas é concebida, sendo que princípios como autonomia escolar, prestação de contas, gestão baseada em resultados, e liberdade de eleição escolar, têm orientado como se regulam, provêm e financiam os serviços educativos (VERGER; NORMAND, 2015).

Diante do quadro apresentado, infere-se que o modelo de gestão gerencial vai se sedimentando no âmbito das políticas educacionais da educação básica do estado, assimilado, portanto, pelos gestores da educação pública, tendo em vista uma educação suposta- mente eficiente e dinâmica, com base em critérios de mérito e resultados.

Outro exemplo é o Programa "Escola da Autoria", estabelecido pela Lei n 4.973 , de 29 de dezembro de 2016, no âmbito do Poder Executivo, que tem como finalidades,

I - executar a Política de Educação Básica, em consonância com as diretrizes: a) nacionais: Constituição Federal de 1998 e a Lei Federal no 9.394, de 20 de dezembro de 1996;

a) nacionais: Constituição Federal de 1988 e a Lei Federal no 9.394, de 20 de dezembro de 1996;

b) estaduais: Constituição do Estado de Mato Grosso do Sul e a Lei Estadual no 4.621, de 22 de dezembro de 2014;

9 "É crucial para o Estado o desenvolvimento da forma política do neoliberalismo, geralmente chamada de Nova Gestão Pública, destacando como uma das suas características-chave o fato de, em conformidade com o neoliberalismo, não funcionar contra o Estado, mas através dele" (DALE, 2010, p. 1104, grifo do autor). 
II - desenvolver ações voltadas à melhoria do ensino e aprendizagem;

III - sistematizar e difundir inovações pedagógicas e gerenciais;

IV - difundir o modelo de educação integral no Estado, que terá por base a ampliação da jornada escolar e a formação integral e integrada do estudante, tanto nos aspectos cognitivos quanto nos sócio emocionais, com base nos pilares: aprender a conhecer, a fazer, a conviver e a ser, segundo as diretrizes definidas pelo Ministério da Educação;

V - Integrar as ações desenvolvidas nas unidades escolares da Rede Pública Estadual de Ensino inseridas no Programa em todo o Estado, oferecendo atividades que contribuam para o processo de aprendizagem e de enriquecimento cultural, bem como estimulando o exercício da cidadania autônoma, solidária e competente; VI promover e apoiar a expansão gradativa do ensino integral para todas as uni- dades escolares da Rede Pública Estadual de Ensino, observado o regulamento próprio;

VI- consolidar o modelo de gestão para resultados nas unidades escolares da Rede Pública Estadual de Ensino, com o aprimoramento dos instrumentos gerenciais de planejamento, acompanhamento e de avaliação;

VII - estimular a participação coletiva da comunidade escolar na elaboração do projeto político-pedagógico da Escola;

VIII- reduzir a média de abandono e de reprovação dos alunos da Rede Pública Estadual de Ensino;

IX- aumentar a taxa de participação na prova do Exame Nacional do Ensino Médio (ENEM) e melhorar o desempenho dos alunos participantes;

X- viabilizar parcerias com instituições de ensino e pesquisa e com entidades públicas ou privadas que visem a colaborar com a expansão Programa de Educação em Tempo Integral, denominado 'Escola da Autoria' (MATO GROSSO DO SUL, 2016, p.6, grifo nosso).

Observam-se nos incisos descritos, finalidades antagônicas no âmbito da proposta, que se apresentam com o objetivo de melhorar a qualidade do ensino. No entanto, a saída indicada, com toda clareza, é o modelo de gestão gerencial, com ênfase nos resultados (OLIVEIRA, 2019).

O deputado estadual, representante da Assembleia Legislativa do Estado de MS, expõe, a sua avaliação sobre a gestão da educação na Rede Estadual de Ensino de MS,

O que tenho observado e recebo de devolutiva de professores e diretores escolares é que a Secretaria Estadual de Educação não tem desenvolvido uma política efetiva para realizar uma gestão democrática no âmbito do sistema estadual de ensino. Os projetos e as políticas educacionais são definidos pelo órgão central e implantados sem uma participação das comunidades escolares destinatárias dos mesmos. Não existem ações voltadas para o envolvimento das escolas, especialmente dos coordenadores pedagógicos, professores e diretores, na definição das políticas educacionais, bem como de ações voltadas para o fortalecimento da autonomia das escolas. Foram criadas 11 CREs (Coordenadorias Regionais de Educação), que são coordenadas por pessoas da confiança da Secretaria, para exercer um papel muito mais de fiscalização e controle das unidades escolares. As escolas, por exemplo, não têm sequer autonomia para convidar alguém para proferir uma palestra aos alunos, se não tiver o aval da CRE. Há muitas reclamações dos professores de que as decisões são tomadas de cima para baixo e que aumentou o nível de controle do órgão central sobre as escolas. (REPRESENTANTE DA ALE/MS, ENTREVISTA, 17/12/2020).

O depoimento apresenta crítica contundente à centralização por parte do órgão central, e indica o recuo da autonomia das escolas e dos professores, considerando-se as situações relatadas. Compreende-se que a participação na tomada de decisão no exercício da gestão democrática é insubstituível, ou seja, 
O poder de decidir, participando democraticamente e com os outros nos respectivos processos de tomada das decisões representa o âmago da democracia e, consequentemente, sem participação na decisão não é possível conceber uma gestão democrática das escolas na perspectiva do seu autogoverno. É mesmo essa dimensão político-participativa decisória que confere sentido e substância às anteriores dimensões de eleição e de colegialidade democráticas (LIMA, 2014, p. 1072-1073).

Diante do quadro apresentado, observam-se concepções antagônicas, gestão gerencial e gestão democrática, no campo da disputa hegemônica por um projeto educacional. Esta disputa "pressupõe indubitavelmente que se deve levar em conta os interesses e as tendências dos grupos sobre os quais a hegemonia será exercida" (GRAMSCI, 1984 p. 33).

Apesar do prazo expirado, o estado não regulamentou, até o momento, a Lei de gestão democrática, atendendo exigências formais da Lei no 13.005, de 2014 (BRASIL, 2014) e da Lei no 4.621 de 2014 (MATO GROSSO DO SUL, 2014), corroborando o que observam Souza e Pires (2018), ao analisarem a legislação das unidades federadas brasileiras, ou seja, de que poucas fazem menção à democratização da gestão do sistema educacional, que pode estar relacionada ao entendimento de que a gestão democrática esteja circunscrita à gestão da escola.

\section{CONSIDERAÇÕES FINAIS}

Buscou-se, neste artigo, analisar o processo de materialização do Plano Estadual de Educação de Mato Grosso do Sul (PEE/MS) 2014-2024, como política pública, de modo a apreender as condições objetivas desse processo, ressaltando as concepções de gestão da educação em disputa, com foco na regulamentação da gestão democrática da educação, atendendo ao disposto no art. 10 da Lei no 4.621, de dezembro de 2014, que aprovou o PEE/MS (MATO GROSSO DO SUL, 2014).

A supracitada lei, confirma a exigência de que a gestão democrática seja normatizada em lei específica, em consonância com o art. $9^{\circ}$ da Lei 13.005, de 25 de junho de 2014, que aprovou o PNE 2014-2024 (BRASIL, 2014).

A análise do processo de materialização do PEE/MS, com apoio nos documentos e nas entrevistas, mostrou as concepções em disputa, em torno de um projeto de gestão educacional. Observou-se, por um lado, mecanismos de gestão democrática, por exemplo, a elaboração coletiva do projeto pedagógico, a presença do colegiado escolar, assim como a criação e garantia de funcionamento do Fórum Estadual de Educação, possibilitados pela Constituição Federal de 1988 e pela de Lei de Diretrizes e Bases da Educação Nacional por outro, a concepção de gestão gerencial é identificada, principalmente, no modelo de avaliação de competências básicas para diretores escolares, definidos como "dirigentes escolares", no controle do trabalho dos diretores, entre outros, por meio da assinatura do Termo de compromisso, como critério para acesso e permanência no cargo de diretor escolar, na contratação de instituição privada sem fins lucrativos para condução do 
processo avaliativo, assim como no Programa denominado "Escola da Autoria".

A Lei Estadual $n^{\circ}$ 5.466, de dezembro de 2019, vigente, focaliza a gestão democrática do Ensino e Aprendizagem e a eleição para diretores escolares, mas não se refere aos dispositivos da gestão democrática da educação para o Sistema de Ensino.

A ausência desses dispositivos, mesmo com mecanismos presentes de gestão democrática no âmbito da escola, indica, contraditoriamente, a concepção de gestão gerencial que vem se tornando hegemônica nas políticas educacionais da educação básica do Estado de Mato Grosso do Sul.

Em que pese todos os municípios do estado terem aprovado os planos municipais, por lei, destaca-se que não foi possível verificar, até o momento, como se encontram os processos de normatização da Gestão democrática nos 79 municípios do estado. No entanto, infere-se que o número seja pequeno, considerando-se que eles são diversos em sua capacidade administrativa, política e financeira, sendo que muitos deles dependem de algum tipo de auxílio para ter o mínimo de autonomia, como analisa Abrucio (2010), e, portanto, podem apresentar mais dificuldades para assumir suas responsabilidades.

Afirma-se a importância do acompanhamento pela Comissão de Monitoramento e Avaliação do PEE/MS e, notadamente, pelo Conselho Estadual de Educação e Fórum Estadual de Educação, de como o estado de MS tem se organizado para regulamentar e definir normas específicas de gestão democrática e, do mesmo modo, acompanhar a sua efetivação, por meio da divulgação de dados e debates públicos, entendendo-se que os educadores comprometidos com a gestão democrática da educação, utilizando os termos de Cury (2013, p. 32), "mais do que ser sujeitos ao processo, querem se estabelecer como sujeitos do processo e, portanto, ampliar a participação atenta e crítica desses sujeitos na formulação e materialização das políticas educacionais em curso, em um projeto de sociedade democrática. 


\section{REFERÊNCIAS}

AFONSO, Almerindo Janela. A(s) autonomia (s) da escola na encruzilhada entre o velho e o novo espaço público. In: LIMA, Licínio Carlos; AFONSO, Almerindo Janela. Reformas da educação pública: democrati- zação, modernização, neoliberalismo. Porto: Edições Afrontamento. 2002, p. 75-89.

AFONSO, Almerindo Janela. Gestão, autonomia e accountability na escola pública portuguesa: breve dia- cronia. Revista Brasileira de Política e Administração da Educação, v. 26, n. 1, p. 13-30, jan./abr. 2010.

ABRUCIO, Fernando Luiz. A dinâmica federativa da federação brasileira: diagnóstico e propostas de aperfei- çoamento. Educação e federalismo no Brasil: combater as desigualdades, garantir a diversidade. Brasília: Unesco, 2010. p. 39-70.

BRASIL. [Constituição (1988)]. Constituição da República Federativa do Brasil. Diário Oficial da União. Brasília 5 out., 1988. Brasília, DF. Disponível em:

http://www.planalto.gov.br/ccivil_03/constituicao/constitui- cao.htm. Acesso em: 20 abr. 2017.

BRASIL. Documento Final da CONAE. Brasília: MEC, 2010a. Disponível em: http://conae.mec.gov.br/ima-ges/stories/pdf/pdf/documetos/documento_final_sl.pdf Acesso em 23 jul. 2015.

BRASIL. Ministério da Administração e reforma do Estado. Plano Diretor da Reforma do Aparelho do Estado. Brasília, DF: MARE, 1995.

BRASIL. Lei no 9.394, de 20 de dezembro de 1996. Estabelece as Diretrizes e Bases da Educação Nacio- nal. Brasília, 1996. Disponível em:

http://www.planalto.gov.br/ccivil_03/leis//9394.htm. Acesso em: 20 set.

2019.

BRASIL. Lei no 10.172, de 9 de janeiro de 2001. Aprova o Plano Nacional de Educação e dá outras provi- dências. Disponível em:

http://www.planalto.gov.br/ccivil_03/leis/leis_2001/10172.htm. Acesso em: 10 maio 2015.

BRASIL. Lei no 13.005, de 25 de junho de 2014. Aprova o Plano Nacional de Educação

- PNE e dá outras providências. Disponível em:

http://www.planalto.gov.br/ccivil_03/_ato2011-2014/2014/lei/l13005.htm. Aces- so em: 20 abr. 2017.

BRASIL. Portaria Ministerial no 1.407. Instituiu o Fórum Nacional de Educação (FNE). Brasília, DF. Diário Oficial da União no 240, de 16 de dezembro de 2010b. Disponível em: http://fne.mec.gov.br/images/doc/Por- taria1407.pdf. Acesso em: set. 2018.

COMISSÃO DE MONITORAMENTO e AVALIAÇÃO DO PEE/MS (CMAPEEMS). $\mathbf{1 0}^{0}$ Relatório de Monitoramento e Avaliação do Plano Estadual de Educação: Sistematização das metas Estratégicas. Campo

Grande: 2017.

CONFERÊNCIA NACIONAL DE EDUCAÇÃO (CONAE). Documento final, 2014. Disponível em: http://co- 
nae2014.mec.gov.br/images/doc/Sistematizacao/DocumentoFinal29012015.pdf

CURY, Carlos Roberto Jamil. Gestão democrática da educação: exigências e desafios. Revista Brasileira de Política e Administração da Educação. Porto Alegre: ANPAE, v. 18, n. 2, jul./ dez., p. 163-174, 2002.

CURY, Carlos Roberto Jamil. Planos Nacionais de Educação no Brasil. In: FERREIRA, Eliza Bartolozzi; FONSECA, Marília. (Org.) Política e Planejamento educacional no Brasil do século 21. Brasília: Liber Livro, 2013.

DALE, Roger. A sociologia da educação e o Estado após a globalização. Educação e Sociedade, Campi- nas, v. 31, n. 113, p. 1099-1120, out.-dez. 2010.

DOURADO, Luiz Fernandes. Avaliação do Plano Nacional de Educação 2001-2009: questões estruturais e conjunturais de uma política. Educação \& Sociedade, Campinas, v. 31, n. 112, p. 677-705, jul.-set. 2010. DOURADO, Luiz Fernandes. Plano Nacional de Educação: o epicentro das políticas de Estado para a educação brasileira. Goiânia: Ed. da Imprensa Universitária/ANPAE, 2017.

DOURADO, Luiz Fernandes; ARAÚJO, WALISSON. Do FNE ao FNPE: a Conape como resistência. Revista Retratos da Escola. Brasília, v.12, n. 23, p. 207-226, jul./out. 2018.

FERNANDES, Maria Dilnéia Espíndola. Gestão democrática da educação no Brasil: a emergência do direito à educação. Curitiba: Appris, 2018.

FRIGOTTO, Gaudêncio. A educação e a crise do capitalismo real. São Paulo:

Cortez,1995. FRIGOTTO, Gaudêncio. Os circuitos da história e o balanço da educação no Brasil na primeira década do

século XXI. Revista Brasileira de Educação, v. 16, n. 46, p. 235-274, jan./abr. 2011.

GRAMSCI, Antonio. Maquiavel, a política e o Estado moderno, 4. ed. Rio de Janeiro: Civilização Brasilei- ra, 1984.

HARVEY, David. O neoliberalismo: história e implicações. São Paulo: Edições Loyola, 2012.

INSTITUTO BRASILEIRO DE GEOGRAFIA E ESTÁTISTICA (IBGE). Cidades e estados: Mato Grosso do Sul. Disponível em: https://www.ibge.gov.br/cidades-e-estados/ms.html Acesso em: 10 set. 2020.

LIMA, Licínio Carlos. Diretor(a) de escola pública: unipessoalidade e concentração do poder no quadro de uma relação subordinada. In: PERONI, V. M. V. (Org.).

Redefinições das fronteiras entre o público e o privado: implicações para a democratização da educação. Brasília: Líber Livro, 2013. p. 58-81.

LIMA, Licínio Carlos. Gestão democrática das escolas: do autogoverno à ascensão de uma pós- democracia gestionária? Educação e Sociedade, Campinas, v. 35, n. 129, p. 1067-1083, out./dez. 2014.

MATO GROSSO DO SUL. COMISSÃO DE MONITORAMENTO e AVALIAÇÃO DO PEE/MS (CMAPEEMS).

Relatório de Monitoramento e Avaliação do PEE/MS - ciclo: 2015-2016. Campo Grande: Secretaria de Estado de Educação de Mato Grosso do Sul, 2018. 
MATO GROSSO DO SUL. Decreto no 14.199, de 28 de maio de 2015. Institui a Comissão de Monitoramento e Avaliação do Plano Estadual de Educação de Mato Grosso do Sul, e dá outras providências. Diário Ofi- cial do Estado, № 8.930, de 29 de maio de 2015. Campo Grande, 2015a.

MATO GROSSO DO SUL. Decreto no 14.281, de 21 de outubro de 2015. Acrescenta os incisos V, VI, VII, VIII, IX e X ao caput do art. 2o do Decreto ํo 14.199, de 28 de maio de 2015, que institui a Comissão de Monitoramento e Avaliação do Plano Estadual de Educação de Mato Grosso do Sul. Campo Grande, 2015b. Disponível em: https://www.jusbrasil.com.br/diarios/102821640/doems-normal-23-10-2015-pg-2 Acesso em: 20 maio 2019.

MATO GROSSO DO SUL. Edital SED/MS n. 19/2019. Avaliação de competências básicas de dirigente esco- lar. Diário Oficial Eletrônico n. 9.986, 13 de setembro de 2019. Campo Grande, 2019a.

MATO GROSSO DO SUL. Lei no 2.787, de 24 de dezembro de 2003. Dispõe sobre o Sistema Estadual de Ensino de Mato Grosso do Sul e dá outras providências. Campo Grande: Secretaria de Estado de Educação de Mato Grosso do Sul, 2004.

MATO GROSSO DO SUL. Lei no 3.244, de 6 de junho de 2006. Dispõe sobre a eleição de diretores, direto- res-adjuntos e do colegiado escolar da Rede Estadual de Ensino de Mato Grosso do Sul e dá outras provi- dências. Campo Grande, 2006.

MATO GROSSO DO SUL. Lei $\mathbf{n}^{0}$ 3.479, de 20 de dezembro de 2007. Dispõe sobre o processo eletivo de dirigentes escolares da rede estadual de ensino, dá nova redação a dispositivo da Lei ํㅜ 3.244, de 6 de junho de 2006, e dá outras providências, Campo Grande, 2007.

MATO GROSSO DO SUL. Lei no 4.621, de 22 de dezembro de 2014. Aprova o Plano Estadual de Educa-

ção de Mato Grosso do Sul e dá outras providências. Disponível em: https://www.sed.ms.gov.br/wp-content/uploads/sites/67/2015/05/pee-ms-2014.pdf/. Acesso em: 10 maio

2018.

MATO GROSSO DO SUL. Lei no 4.696, de 13 de julho de 2015. Dá nova redação ao art. 13, ao caput e ao inciso I do art. 14 e ao inciso III do art. 16, todos da Lei no 3.244 , de 6 de julho de 2006; dá nova redação aos arts. 5e e 6을 e acrescenta 0 art. 5-A à Lei no 3.479, de 20 de dezembro de 2007. Campo Grande, 2015c.

MATO GROSSO DO SUL. Lei n0 4.973, de 29 de dezembro de 2016. Cria o programa de Educação em Tempo Integral, denominado "Escola da Autoria", e dá outras providências. Diário Oficial n0 9.318, 30 dez. 2016. Campo Grande, 2016.

254

MATO GROSSO DO SUL. Lei 5.466, de 18 de dezembro de 2019. Dispõe sobre a Gestão Democrática do Ensino e Aprendizagem, sobre o processo de seleção dos dirigentes escolares e dos membros do Colegia- do Escolar, no âmbito da Rede Estadual de Ensino de Mato Grosso do Sul, e dá outras providências. Diário Oficial Eletrônico $\mathrm{n}^{\mathrm{O}}$ 10.054, de 18 de dezembro de 2019. Campo Grande, 2019b. 
OLIVEIRA, Dalila Andrade. Nova gestão pública e governos democráticos-populares: contradições entre a busca da eficiência e a ampliação do direito à educação. Educação \& Sociedade, Campinas, v. 36, n. 132, p. 625-646, jul./set. 2015.

OLIVEIRA, Regina Tereza Cestari. A Lei de Diretrizes e Bases da Educação Nacional: tramitação legislativa e aspectos principais. Nuances: Revista do Curso de Pedagogia. Presidente Prudente, v. 4, n. 4, p. 25-34, 1998.

OLIVEIRA, Regina Tereza Cestari. Políticas e prioridades para a educação básica dos governos estaduais eleitos em 2018: o Estado de Mato Grosso do Sul em questão. In: ADRIÃO, Theresa; MARQUES, Luciana Rosa; AGUIAR, Marcia Ângela S. Políticas e prioridades para a educação básica dos governos estaduais eleitos em 2018: para onde os governos estaduais caminham? (Org.). Meio eletrônico. Brasília: ANPAE, 2019. p. 299-314.

PERONI, Vera Maria; OLIVEIRA, Regina Tereza Cestari; FERNANDES, Maria Dilnéia Espíndola. Estado e Terceiro Setor: as novas regulações entre o público e o privado na gestão da educação brasileira. Revista Educação \& Sociedade. Campinas: CEDES, v. 30, n. 108, p. 761-778, 2009.

PERONI, Vera Maria Vidal. A gestão democrática da educação em tempos de parceria entre o público e o privado. Pro-Posições: Revista Quadrimestral da Faculdade de Educação/Unicamp. Campinas, v. 23, n.2 (68), p. 19-31, maio/ago. 2012.

SCAFF, Elisangela Alves da Silva; OLIVEIRA, Regina Tereza Cestari. Fóruns de Educação: instrumentos de participação e representação na gestão educacional brasileira. In: OLIVEIRA, Regina Tereza Cestari. Edu- cação e Democracia: políticas e direitos sociais. Campo Grande, MS: Ed. Oeste, 2019.

SOUZA, Ângelo Ricardo. Políticas de democratização da gestão educacional no Brasil: experiência e expec- tativa com o novo Plano Nacional de Educação. Revista Pedagógica, Unochapecó, v. 18, p. 111-128, 2016.

SOUZA, Ângelo Ricardo; PIRES, Pierre André Garcia. As leis de gestão democrática da Educação nos esta- dos brasileiros. Educar em Revista, Curitiba, Brasil, v. 34, n. 68, p. 65-87, mar./abr. 2018.

VERGER, Antoni; NORMAND, Romuald. Nueva gestión pública e educacion: elementos teóricos y concep- tuales para el estúdio de um modelo de reforma educativa global.

Educação e Sociedade. Campinas, v. 36, n. 132, p. 625-646, jul.-set., 2015.

VIEIRA, Evaldo Amaro. A política e as bases do direito educacional. Cadernos Cedes, ano XXI, n. 55, p. 9-29, nov. 2001.

\section{ENTREVISTAS:}

REPRESENTANTE DA ASSEMBLEIA LEGISLATIVA DO ESTADO DE MATO GROSSO DO SUL. [Entrevista]. Entrevista realizada com o presidente da Comissão de Educação, da Assembleia Legislativa de Mato Grosso do Sul, por Regina Tereza Cestari de Oliveira, 17/12/2019.

REPRESENTANTE DA SECRETARIA DE ESTADO DE EDUCAÇÃO DE MATO GROSSO DO SUL. [Entrevista]. Entrevista realizada com o presidente da Comissão de Monitoramento e Avaliação do Estado de Mato Grosso do Sul, por Regina Tereza Cestari 
de Oliveira, 09/01/2020.

REPRESENTANTE DO FÓRUM ESTADUAL DE EDUCAÇÃO DE MATO GROSSO DO SUL. [Entrevista].

Entrevista realizada com o presidente do Fórum Estadual de Educação de Mato Grosso do Sul, realizada por Regina Tereza Cestari de Oliveira, 07/02/2020. 